\title{
Designing with biodiversity data: connections among design, materials, and technology
}

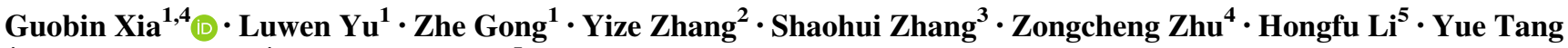 \\ $4 \cdot$ Yinghua Huang ${ }^{4} \cdot$ Zhendong Tian $^{5}$
}

Received: 16 February 2021/Accepted: 12 August 2021/Published online: 24 August 2021

(c) The Author(s) 2021

\begin{abstract}
Data visualisation plays an integral role in the communication of complex data between expert and nonexpert audiences. However, heretofore, large uncertainties remain concerning how people understand and interact with massive amounts of data. In this paper, we describe the design and evaluation of a series of interactive data physicalising installations, aim to evaluate the potential influence of technology upon traditional comprehension of material items, its connection to meaning and value, and how technology that allows for an extension of this thinking builds an emotional connection between audiences and the intangible object, 'data'. The design of prototypes was driven by data of the three least appearing species in Scotland. Analysis of 60 audience members' responses reveals the positive design potential of further exploring innovative design methods to engage people with data. Likewise, the results provide empirical evidence regarding hands-on experience with integrative data visualisation in a realistic scenario and suggest that inventive forms of visualisation could potentially trigger people's emotional and memorial reactions, which may affect their decision making at an unconscious level
\end{abstract}

Guobin Xia

sdgx@leeds.ac.uk

School of Design, University of Leeds, Leeds, UK

2 School of Language, Cultures and Societies, University of Leeds, Leeds, UK

3 School of Forest Science, University of Eastern Finland, Kuopio, Finland

4 Edinburgh College of Art, The University of Edinburgh, Edinburgh, UK

5 School of Informatics, The University of Edinburgh, Edinburgh, UK
Keywords Data visualisation - Human-Data Interaction · Design with data

\section{Introduction}

The user experience of data communication is confined to interaction by keyboard or touch-screen systems because of the conventional data visualisation method: text panels. However, in recent years, the rapidly developing, datadriven society has witnessed the sprouting of a more modern and efficient approach to data visualisation as well as interaction with intangible objects. Within this approach emerges a rather uncharted research area in the HumanComputer Interaction (HCI) field: Human-Data Interaction (HDI), a subject focused on rendering interaction mechanisms between users and data with a comprehensive data collection and processing system [5]. Questions that this article deems important and attempts to answer are (1) Could the possible merit of data materialisation be conducive to both the fathoming of and interaction with a massive amount of data? (2) How does technology which allows for an extension of this thinking build an emotional connection between audiences and the intangible object, 'data'?

It is made clear in previous studies which focus on the display location of casual information (e.g. in the corridors of office buildings, student dormitories or networking events) that those semi-public locations share a common logic - the targeted audience mainly consists of people who share some distinct features; thus, the location is conducive for publicity $[8,10,13,15]$. In comparison, venues such as museums are recognised as public spaces where the functions of collection, research, exhibition and recreation are served [23]; they are especially important as sites for 
educational purposes as well, where individuals with manifold backgrounds can receive educational information. However, some deem that the museum audience is rather diverse considering its nature as a tourist attraction for short and mainly non-repeating tourists [2, 24]. Some museum studies reveal the way that tourists experience interactive exploration in the museum and how those interactivities can be further augmented [3, 19]. More importantly, Sheng and Chen [23] also indicate that perceived experiential value is a key construct which can ascertain the success or failure of a user's overall museum experience. Reviewing the previous studies, it can be concluded that experiential value generation in a museum context includes and requires several key aspects including entertainment, enjoyment, visual appeal and escapism $[16,18]$. According to Bailey et al. [4], strong motivating factors surrounding users' intentions to visit museums include leisure, learning, new experiences and entertainment in an engaging, stimulating environment. However, the enhancing ability of abstract and interactive information visualisation in both exhibition content and tourist attraction has not yet been studied.

Practical data visualisation involves manifold aspects, amongst which, data analysis is, more often than not, prioritised over its aesthetic concerns in terms of functionality; however, in a relatively casual, public context, the ambient data visualisations are valued mainly for their aesthetic merit in enriching the surroundings, like paintings or other similar forms of art. Thus, it is evident that data visualisation is of great importance to museums in terms of visual attractiveness for its role in arousing tourists' motivation to visit the visual exhibition in the first place, increasing the amount of time they spend exploring and enhancing the conveyance of the information it displays. For places like museums and galleries, such visually appealing, interactive visualisation has been utilised in a more accessible manner, such as a floating numbers installation, which depicts a dynamic stream of information by presenting a 'river' of numbers flowing across an interactive tablet. For example, Artviz is an interface designed by Dumas et al. [11]. It combines sophisticated visualization techniques and tangible interactions that allow users to navigate a large collection of artwork on a graphical display exploiting USB-controlled plug-and-play hardware components. Another example named measuring cup, a data form project by Rezaeian and Donovan [22]. It presents 150 years of Sydney temperature data in a cupshaped object about $6 \mathrm{~cm}$ high. Additionally, Al-Megren and Ruddle [1] developed a Tangible User Interface (TUI) for interactive data visualization focuses on studying a more effective strategy using TUI. Their results demonstrate that participants found patterns faster with the TUI than the multi-touch interface. Collectively, this research motivates us to use $3 \mathrm{D}$ printing, computer and sensor programming for our work.

This study looks at a relatively new area which has emerged from integrative studies of digital network technologies, data materialisation, and human-data interaction (HDI). Moreover, this work is also relevant to current studies on information visualisation in public spaces since the particular difficulties for museums being integrated with information visualisation techniques are examined and discussed. The main aim of this study is to evaluate the potential influence of technology upon traditional comprehension of material items, its connection to meaning and value, and how technology allows for an extension of this thinking and makes the visualisation memorable, and as such, provide an empirical basis for innovative datadriven design approaches.

\section{Prototypes}

This project is part of a series of investigations by National Trust for Scotland (NTS) into exploiting innovative datadriven design approaches to encourage people to explore, communicate and understand biodiversity data in science museums. In this work, we aim to evaluate the potential influence of technology upon traditional comprehension of material items, its relationship to meaning and value, and how technology allows for an extension of this thinking and builds an emotional connection between audiences and the data in informal learning spaces. Specifically, we investigate how biodiversity data visualisation, combined with materials, sensing and display technologies, can be conceived to encourage and support understanding as well as participation.

The design of the prototypes took advantage of an empirical framework from HDI research; that is, it was designed from, with and by data [25]. Moreover, the work was also driven by research that exploits the inherent qualities of tangible interaction as a medium to illuminate complicated concepts. Beyond designing and developing physical installations to invite audiences to communicate and understand the species data, the intention was to gather data from people to better understand their behaviour, and as such, potentially engage the advancement of effective travelling decision-support. We herein describe the design and functions of the prototypes for the materialisation of the data for the three least appearing species in Scotland.

\subsection{Dataset}

The raw species dataset used in this project was provided by the NTS, involving the geographic distribution and occurrence records of over 76,000 species in Scotland. 


\subsection{Data selection}

Initially, we analysed all occurrence records and changes of species in the last 20 years in Scotland through Python. The three least recorded species (hawfinch, little mouseear, and snuff fungus) were chosen and visualised on the map of Scotland (Fig. 1).

\subsection{Visualisation and design}

The design of prototypes was profoundly influenced and motivated by previous integrative studies of HDI research and light-emitting diode (LED) arts that investigate the correlation between visual perception and psychological engagement $[6,7,9,12,14,17,20]$. We first utilised Python to calculate and visualise the data of the three species on the maps of Scotland. Then, the conceptual models were created by Rhino based on the occurrence records and geographic distribution data of species. The curves of the longitudinally arrayed pieces on the map were explicitly designed for indicating the occurrence records of the species in particular areas, and their positions represent the species' geographic distribution (Fig. 2).

\subsection{Production, visualisation and interaction}

During the production process, several techniques were employed together, involving laser cutting, circuit design and 3D printing, as well as computer and sensor programming. Physical installations were made from acrylic pieces and LED cubes (Fig. 3). The white boxes at the bottom of each installation were $50 \mathrm{~cm} \times 50 \mathrm{~cm}$. Maps of Scotland were created by $3 \mathrm{D}$ printer and were pasted on the top of the boxes. The longitudinally arrayed acrylic pieces with various curves were laser cut. Each of the installations was equipped with a screen that provided additional species information and relational data (Fig. 3d).

The actual interaction with the installations was explicitly designed in terms of people's natural behaviour Specifically, when audiences approached and looked at the

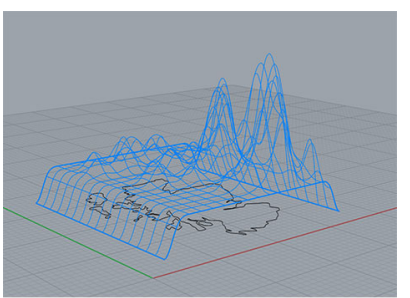

(a)

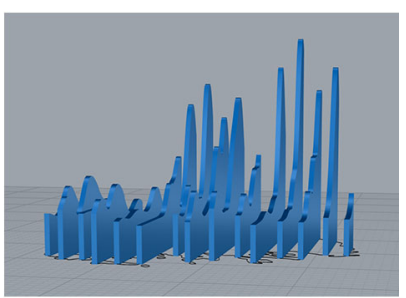

(b)

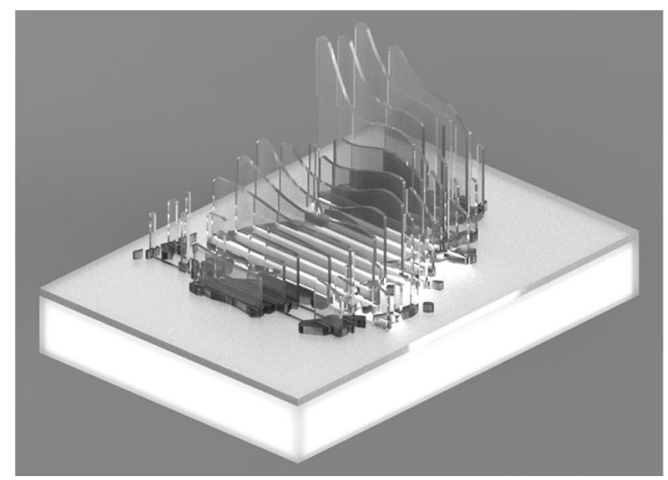

(c)

Fig. 2 Three dimensional models created by Rhino

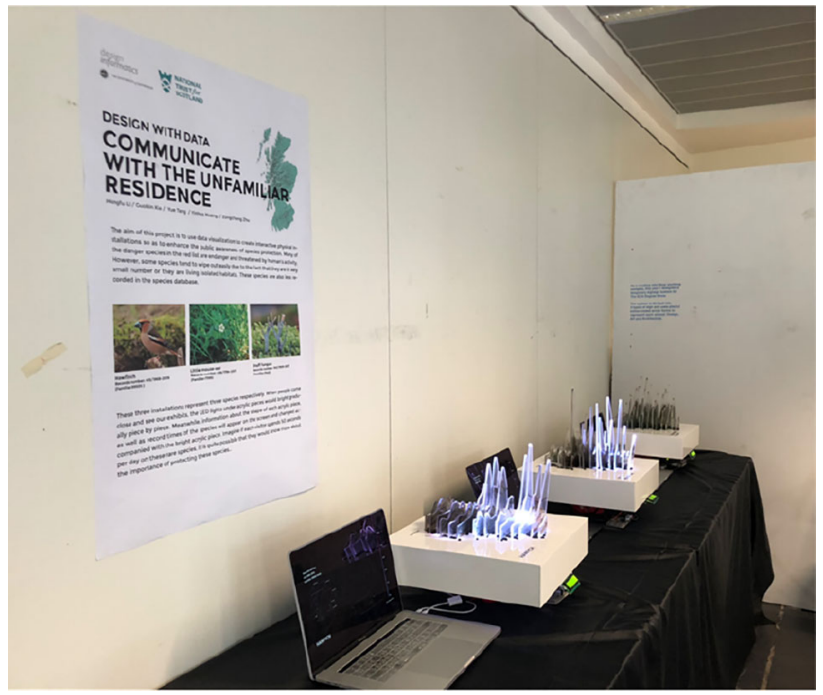

Fig. 3 Physical installations
Fig. 1 Three image markers for geographic distributions of species: (a) Hawfinch; (b) Little mouse-ear; (c) Snuff fungus

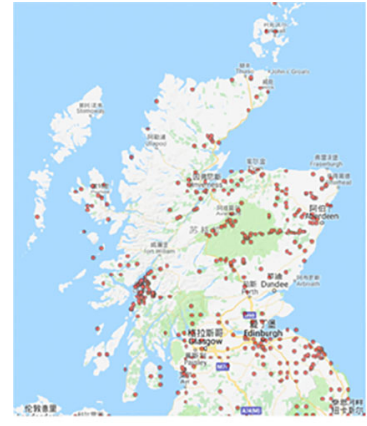

(a)

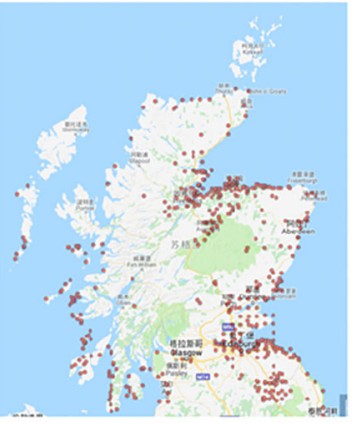

(b)

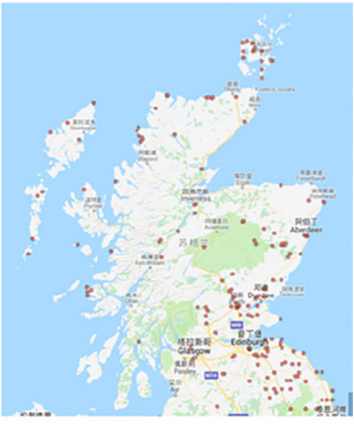

(c) 
installations, the acrylic pieces lit up piece by piece. The information regarding each acrylic piece was presented on the screen. To support the lighting interaction and gather data from audiences, ultrasonic sensors were used to detect people's distance whilst record their viewing time for each installation.

After interacting with the installations, people could use their phones to scan the QR code on the wall. Information regarding how much time they had spent on each species as well as species' geographic information was sent to their phone (Fig. 4).

\section{Evolution}

To quantitatively evaluate the effectiveness of the visualisation, as well as the contributions to this work of educational data-driven design methods, we developed a user test questionnaire (Table 1) based on questions from the Museum Experience Scale (MES) by Othman [21], focusing particularly on measuring people's cognitive components. Specifically, the questionnaire was used to indicate to what extent audiences agreed with statements about their attitudes towards interactive visualised data, compared to the viewing of the original visualised data with a text-based content. For each statement, they circled one of the responses: 'Strongly Disagree' (coded as 1), 'Disagree' (coded as 2), 'Neutral' (coded as 3), 'Agree' (coded as 4), and 'Strongly Agree' (coded as 5). In particular, four components of experience emerged from the improved MES (IMES) questionnaire: engagement with the data knowledge/learning gain from understanding and information discoveries meaningful experience from the interaction with the data emotional connection with the context and content of the data.

The installations were tested at an exhibition held by the Edinburgh College of Arts at the University of Edinburgh. Audiences were students and academic staff from Edinburgh College of Arts equipped with design, digital media, and informatics related backgrounds.
Sixty people, 28 males and 32 females, all with design relevant backgrounds, were invited to test the prototype. We evaluated informatics designers' responses to our prototypes due to our interest in providing empirical design experiences for designers. We wanted them to know whether a visualisation system with materials, sensing and display technologies can be effectively conceived to encourage and support understanding and participation.

Participants were divided into two groups with equal numbers: Group A (the non-interactive group, which had 30 participants including 17 females and 13 males) and Group B (the interactive group, which had 30 participants including 15 females and 15 males). Participants in Group A were then asked to view the paper version of visualised data on the wall and read the additional text-based information provided by the study. People in Group B were asked to view the interactive version with the prototypes. At the end of the session, all of them were asked to complete the IMES questionnaire. The results of the 60 participants' questionnaires were taken into account to evaluate the prototypes.

\section{Results and analysis}

\subsection{General trends}

Comparison was made between participants from Group A and Group B. Different trends between Group A and Group B are displayed in Fig. 5. Analysis was performed using Python, and the results of the pairwise comparisons of a total of 60 individuals are listed in Table 2. $T$ test was exploited to reveal the statistical significance of the differences between Group A and Group B. Generally, it can be concluded that there were significantly higher mean scores across all four components for Group B. To be specific, Fig. 5 shows significantly higher $(N=60$, $p<0.005)$ participants' engagement, knowledge/learning, meaningful experience and emotional connection in Group B than Group A.
Fig. 4 Sample information sheet received by users via scanning the QR code.

(a) Hawfinch, (b) Little mouseear, (c) Snuff fungus

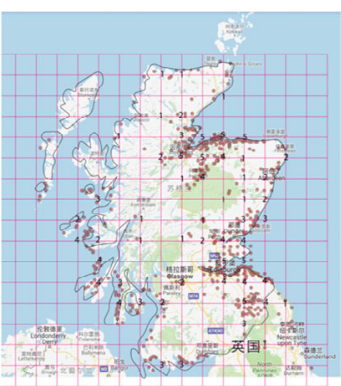

(a) Hawfinch

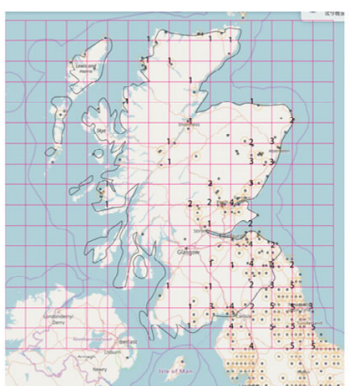

(b) Little mouse-ear

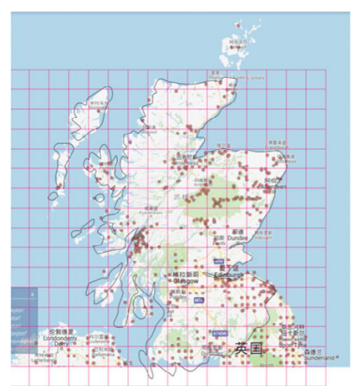

(c) Snuff fungus 
Table 1 Improved Museum Experience Scale (IMES)

\begin{tabular}{|c|c|}
\hline Engagement & Knowledge/Learning \\
\hline $\begin{array}{l}\text { I enjoyed visiting the exhibition in relation to biodiversity } \\
\text { data }\end{array}$ & The information provided about the data exhibits was clear \\
\hline I felt engaged with the data & I could make sense of most of the things I saw and did at the exhibition \\
\hline My visit to the data exhibition was very interesting & I liked the graphics associated with the exhibition \\
\hline $\begin{array}{l}\text { I felt I was experiencing the data exhibition, rather than just } \\
\text { visiting it }\end{array}$ & My visit enriched my knowledge and understanding of specific biodiversity data \\
\hline My visit to the exhibition was inspiring & I discovered new information in relation to species from the exhibits \\
\hline Meaningful Experience & Emotional Connection \\
\hline $\begin{array}{l}\text { During my visit, I was able to reflect on the significance of } \\
\text { the data in the design and their meaning }\end{array}$ & $\begin{array}{l}\text { The exhibition enabled me to evoke my emotions and memories, which may lead } \\
\text { me to places that I might be unconsciously interested in }\end{array}$ \\
\hline $\begin{array}{l}\text { During my visit, I put a lot of effort into thinking about the } \\
\text { biodiversity data }\end{array}$ & $\begin{array}{l}\text { My sense of being in the data was stronger than my sense of being in the real } \\
\text { world }\end{array}$ \\
\hline $\begin{array}{l}\text { Seeing the data materialisation prototypes gave me a sense } \\
\text { of wonder about the exhibition }\end{array}$ & I was overwhelmed with the aesthetic/beauty aspect of the data \\
\hline $\begin{array}{l}\text { After visiting the exhibition, I was still interested to know } \\
\text { more about the topic of the three species }\end{array}$ & I wanted to own exhibits like those that I saw in the exhibition \\
\hline $\begin{array}{l}\text { Seeing real data exhibits of importance was the most } \\
\text { satisfying aspect of my visit to the exhibition }\end{array}$ & I felt connected with the data \\
\hline
\end{tabular}

*Reponses were based on a five-point scale with $1=$ not at all and $5=$ very much

*Positive scale: $4-5$; Negative scale: 1-2

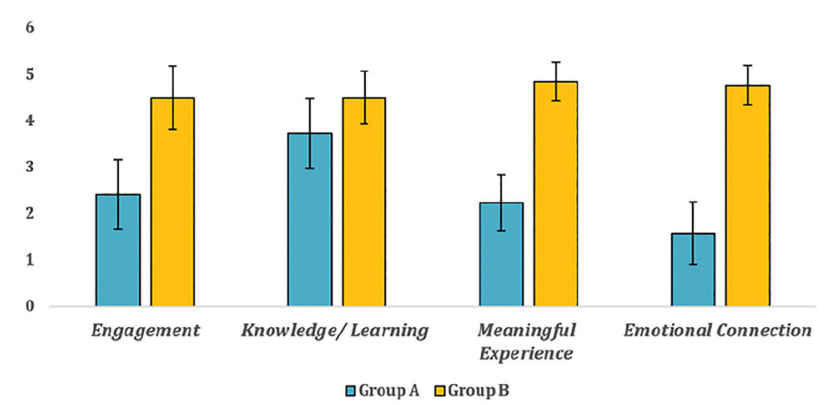

Fig. 5 Mean \pm standard error of participants' responses in terms of mean engagement, knowledge/learning, meaningful experience and emotional connection scores as measured by IMES between Group A (blue bars) and Group B (orange bars)

\subsection{Trend by gender}

Further analysis was carried out to explore the gender differences in participants' engagement, knowledge/learning, meaningful experience, and emotional connection. Different trends between male and female participants in Group A and Group B are displayed in Fig. 6a, b. Pairwise comparison results of gender differences are listed in Table 3. Interestingly, there was a significant difference in the scores of emotional connection in Group A between male $(M=4.75, \mathrm{SD}=0.44)$ and female $(M=4.75, \mathrm{SD}=$ 0.44) participants; specifically, female participants' emotional connection responses were significantly higher than
Table 2 Pairwise comparisons for IMES questionnaire between Group A and Group B

\begin{tabular}{ll}
\hline Pairs & Sig. (2-tailed) \\
\hline Pair 1 Engagement & $0.000^{*}$ \\
Pair 2 Knowledge/Learning & $0.000^{*}$ \\
Pair 3 Meaningful Experience & $0.000^{*}$ \\
Pair 4 Emotional Connection & $0.000^{*}$ \\
\hline
\end{tabular}

*Statistically significant $(p \leq 0.05)$

male participants $(N=60, p \leq 0.05)$. No statistical significance of the differences in other pairwise comparisons was detected.

\section{Discussion}

This research explores the cultural and technical implications of developing solutions that integrate studies of digital network technologies, data materialisation and HDI, with particular concentration on studying how biodiversity data visualisation, combined with materials, sensing and display technologies can be conceived to encourage and support understanding and participation, and how technology that allows for an extension of this thinking builds 


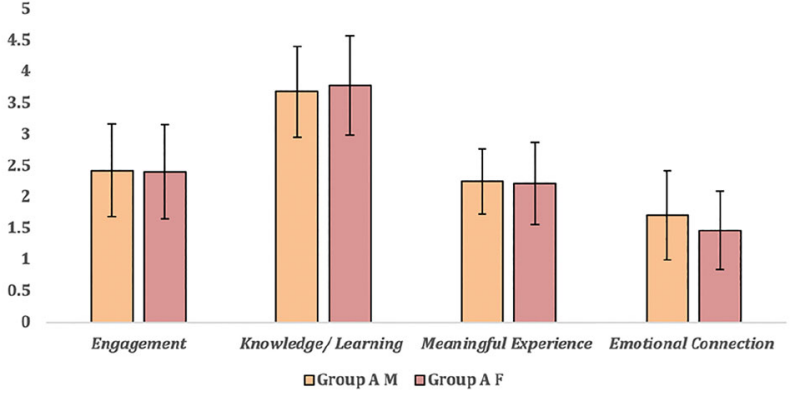

a

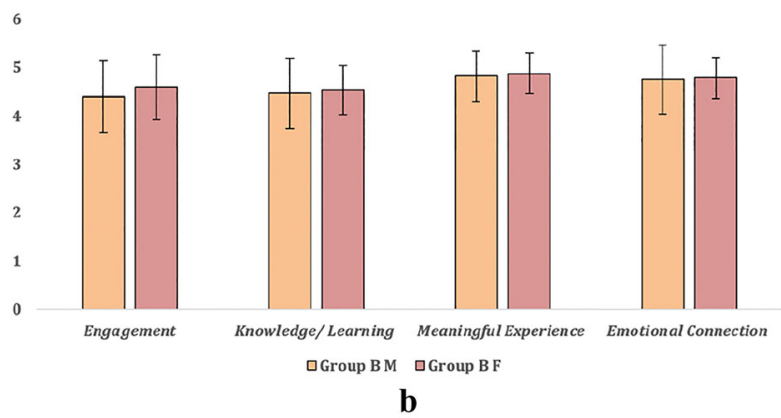

Fig. 6 a, b Mean \pm standard error of male and female participants' responses in terms of mean engagement, knowledge/learning, meaningful experience, and emotional connection scores, as measured by IMES between male (green bars) and female (orange bars)

an emotional connection between the audience and the data visualisation.

Our observations based on IMES revealed specific patterns of how audiences understand and interact with a massive amount of biodiversity data and how the visual and interactive design influence people's engagement, knowledge/learning, meaningful experience, and emotional connection to data visualisation in informal learning spaces.

\subsection{Engagement}

Engagement comes from the 'user experience' (UX) and can be defined by the quality of the UX with the technology. It comprises of attention, novelty, interest, control, feedback, challenge and motivation. In informal learning environments, including museums and art galleries, positive learning outcomes occur as participants are stimulated whilst engaging with the exhibits [26]. However, the relationship between engagement and interactive data exhibits and how it relates to the learning of data is ambiguous. Results of our questionnaire show a statistically significant difference between Group A $(M=2.41$, $\mathrm{SD}=0.74)$ and Group B $(M=4.50, \mathrm{SD}=0.68)$ in the engagement component (Fig. 5). Specifically, Fig. 5 shows that Group B's engagement was significantly greater than Group A's.

$\mathrm{We}$, therefore, suggest that supporting biodiversity data exploration with a combination of materials, sensing, and display technologies can effectively trigger audiences' engagement with the biodiversity data more than the traditional way of data visualisation. However, participants' sense and level of engagement with exhibitions and exhibits in informal learning spaces vary between people and might be induced by a range of elements including prior knowledge, motivation, interest, technology and time spent in the exhibition. Our findings in relation to engagement may suggest many fruitful directions for future research for a positive data learning experience in informal learning spaces.

\subsection{Knowledge and learning}

Observations of the IMES results (Fig. 5) show that participants' knowledge and learning experience is the highest in both groups among all the four components, and the interactive data materialisation $(M=4.50, \mathrm{SD}=0.57)$ group demonstrates more positive responses than the traditional non-interactive data group $(M=3.73, \mathrm{SD}=0.76)$. It is suggested that both traditional data visualisation, as well as interactive data materialisations, can promote people's knowledge and learning experience. Furthermore, observations also suggest data, as an intangible object, combined with materials, sensors, interaction, and display technologies, do indeed improve knowledge acquisition of audiences in informal learning environments.

\subsection{Meaningful experience}

Meaningful experience is one of the foremost purposes of data visualisation. To visualise a massive amount of data
Table 3 Pairwise comparisons for IMES questionnaire between male and female of Group A and Group

\begin{tabular}{lll}
\hline Pairs & Group A Sig. (2-tailed) & Group B Sig. (2-tailed) \\
\hline Pair 1 Engagement & 0.861 & 0.297 \\
Pair 2 Knowledge/Learning & 0.229 & 0.626 \\
Pair 3 Meaningful Experience & 0.415 & 0.745 \\
Pair 4 Emotional Connection & $0.015^{*}$ & 0.769 \\
\hline
\end{tabular}

*Statistically significant $(p \leq 0.05)$ 
and create a meaningful experience, the design of the presentation of the data should make it easy for audiences to understand it. It should attract people's attention and at the same time engage its audience. Data should be presented in moderation, as neither too complex that it could bore visitors nor too sparse that it could fail to communicate with them at all. The design should create interesting tensions to challenge and stimulate visitors. Results in relation to the component of meaningful experience evaluate the level of the data visualisation's promotion of audiences' awareness, curiosity, interest, and understanding of the biodiversity data. From the results (Fig. 5), it is obvious that visualising hidden information pertaining to the data for the interactive group $(M=4.85, \mathrm{SD}=0.52)$ can have a more positive influence on people's awareness, curiosity and desire to know more about the species data than the non-interactive group $(M=2.23, \mathrm{SD}=0.77)$. Additionally, the meaningful experience component is the second most statistically significant of the differences between Group B and Group A.

\subsection{Emotional connection}

The emotional connection component focuses on evaluating the aesthetic value, the profound impact of the data on audiences, the actual design of the memory of the experience for the participant, and the sense of emotional engagement with the data. Interestingly, our results from Fig. 5 indicate significantly higher responses of Group B in the component of emotional connection than Group A, suggesting that interacting with the data can effectively evoke people's emotions and memories and, therefore, may lead them to subjects that they might be unconsciously interested in. Moreover, the result of the emotional connection component is the most statistically significant of the differences between Group A $(M=1.58, \mathrm{SD}=0.67)$ and Group B $(M=4.77, \mathrm{SD}=0.43)$. It can be said, therefore, that maximising the triggering of people's emotional connection with data might potentially give opportunities to enrich the overall experience for museum users. Specifically, the statistical significance of the difference observed in the pairwise comparisons for the IMES questionnaire between male $(M=1.71, \mathrm{SD}=0.71)$ and female $(M=1.35, \mathrm{SD}=0.56)($ Fig. $6 \mathrm{a} ; N=60, p \leq 0.05)$ suggests that there might be gender differences in emotional connections regarding data visualisation.

Overall, these findings provide a potential mechanism for developing solutions that integrate digital network technologies with established practical design methods. The proposed project exploited practical design methods of working with data and demonstrated the concept of a dualism between the material and immaterial nature of things that has previously meant that material objects were separate from their data. Moreover, the project took advantage of an empirical framework from HDI research; that is, it was designed from, with, and by data. Clearly, designing from data helps designers to see when the use of established ethnographic and design methods for gathering data are required. Designing with data enables designers to present sustained flows of data. Designing by data uses data produced by people and allows that data to help people to make decisions at an unconscious level. The potential of this research also provides a set of interesting general guidelines and reflections about the design of new tyles of TUI applications to help people understand and interact with data. Moreover, the methodology used in this project offers a basis for future ongoing TUI research. In the future, the intention is to extend the software and hardware to make it suitable for a diverse range of data visualization. The future research will focus on developing a system based on the presented artefact, showing how objects can be shaped by data rather than human beings. The system could be potentially employed in any informal learning place, including museums, galleries and nature parks with precious species.

Acknowledgements We would like to thank the National Trust for Scotland and Edinburgh College of Arts for making this project possible. Thanks to all members from Edinburgh College of Arts for their insightful comments and suggestions.

\section{Declarations}

Conflict of interest The authors declared no potential conflicts of interest with respect to the research, authorship, and/or publication of this article.

Open Access This article is licensed under a Creative Commons Attribution 4.0 International License, which permits use, sharing, adaptation, distribution and reproduction in any medium or format, as long as you give appropriate credit to the original author(s) and the source, provide a link to the Creative Commons licence, and indicate if changes were made. The images or other third party material in this article are included in the article's Creative Commons licence, unless indicated otherwise in a credit line to the material. If material is not included in the article's Creative Commons licence and your intended use is not permitted by statutory regulation or exceeds the permitted use, you will need to obtain permission directly from the copyright holder. To view a copy of this licence, visit http://creativecommons. org/licenses/by/4.0/.

\section{References}

1. Al-Megren S, Ruddle RA (2016) Comparing tangible and multitouch interaction for interactive data visualization tasks. In: Proceedings of the TEI'16: Tenth International Conference on Tangible, Embedded, and Embodied Interaction, pp 279-286

2. Alelis G, Bobrowicz A, Ang CS (2015) Comparison of engagement and emotional responses of older and younger adults interacting with $3 \mathrm{D}$ cultural heritage artefacts on personal devices. Behav Inform Technol 34(11):1064-1078 
3. Antón C, Camarero C, Garrido M-J (2018) Exploring the experience value of museum visitors as a co-creation process. Curr Issue Tour 21(12):1406-1425

4. Bailey E, Bronnenkant K, Kelley J, Hein G (1998) Visitor behavior at a constructivist exhibition: evaluating investigate! at Boston's Museum of Science. Comm. for Ed. \& Cultural Action, 149-168.

5. Beghelli A, Huerta-Cánepa G, Segal R (2019) Data materialisation: a new undergraduate course for a data driven society. In: Proceedings of the Design Society: International Conference on Engineering Design, vol 1, no 1. Cambridge University Press, pp 2061-2070

6. Berns RS (2011) Designing white-light LED lighting for the display of art: a feasibility study. Color Res Appl 36(5):324-334

7. Bertin J (2011) Graphics and graphic information processing. Walter de Gruyter

8. Brignull H, Rogers Y (2003) Enticing people to interact with large public displays in public spaces. Interact 3:17-24

9. Burke M, Ockwell D, Whitmarsh L (2018) Participatory arts and affective engagement with climate change: the missing link in achieving climate compatible behaviour change? Glob Environ Chang 49:95-105

10. Churchill E, Nelson L, Denoue L, Murphy P, Helfman J (2003) The plasma poster network. Public and situated displays. Springer, Dordrecht, pp 233-260

11. Dumas B, Moerman B, Trullemans S, Signer B (2014) ArtVis: combining advanced visualisation and tangible interaction for the exploration, analysis and browsing of digital artwork collections. Paper presented at the Proceedings of the 2014 International Working Conference on Advanced Visual Interfaces

12. Edmonds E (2011) Art, interaction and engagement. In: 2011 15th International Conference on Information Visualisation. IEEE, pp 451-456

13. Hinrichs U, Schmidt H, Carpendale S (2008) EMDialog: bringing information visualization into the museum. IEEE Trans Visual Comput Graphics 14(6):1181-1188

14. Jansen Y, Dragicevic P, Fekete JD (2013) Evaluating the efficiency of physical visualizations. In: Proceedings of the SIGCHI conference on human factors in computing systems, pp 2593-2602

15. Karahalios K, Donath J (2004) Telemurals: linking remote spaces with social catalysts. In: Proceedings of the SIGCHI conference on human factors in computing systems, pp 615-622
16. Kuo N-T, Cheng Y-S, Chang K-C, Hu S-M (2018) Assessing the asymmetric impact of interpretation environment service quality on museum visitor experience and post-visit behavioral intentions: a case study of the National Palace Museum. Asia Pacific J Tourism Res 23(7):714-733

17. Le Goc M, Perin C, Follmer S, Fekete J-D, Dragicevic P (2018) Dynamic composite data physicalization using wheeled microrobots. IEEE Trans Visual Comput Graphics 25(1):737-747

18. Mathwick C, Malhotra N, Rigdon E (2001) Experiential value: conceptualization, measurement and application in the catalog

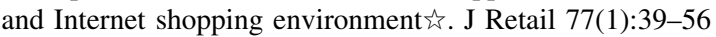

19. Moorhouse N, Jung T (2017) Augmented reality to enhance the learning experience in cultural heritage tourism: An experiential learning cycle perspective. eReview of Tourism Research 8

20. Mortier R, Haddadi H, Henderson T, McAuley D, Crowcroft J, Crabtree A (2020) 41. Human-Data Interaction. The Encyclopedia of Human-Computer Interaction, 2nd edn. Available at: https://www.interaction-design.org/literature/book/the-encyclope dia-of-human-computer-interaction-2nd-ed/human-datainteraction

21. Othman MK (2012) Measuring visitors' experiences with mobile guide technology in cultural spaces. University of York

22. Rezaeian A, Donovan J (2014) Design of a tangible data visualization. In: Proceedings of the 7th international symposium on visual information communication and interaction, pp 232-235

23. Sheng C-W, Chen M-C (2012) A study of experience expectations of museum visitors. Tour Manage 33(1):53-60

24. Tilahun SL, Goshu NN, Ngnotchouye JMT (2017) Prey predator algorithm for travelling salesman problem: application on the Ethiopian tourism sites. In handbook of research on holistic optimization techniques in the hospitality, tourism, and travel industry. IGI Global, pp 400-422

25. Victorelli EZ, Dos Reis JC, Hornung H, Prado AB (2020) Understanding human-data interaction: literature review and recommendations for design. Int J Hum Comput Stud 134:13-32

26. YYusoff Z, Dahlan HM (2013) Mobile based learning: an integrated framework to support learning engagement through Augmented Reality environment. In: 2013 international conference on research and innovation in information systems (ICRIIS). IEEE, pp 251-256 